with acknowledged experts on equal terms. An excellent pianist, he was devoted to music and composed about 30 piano sonatas. It was in accord with his character that he was especially attracted by the work of composers who, like Schubert, took a theme and followed it through many variations.

Peter Caldwell's exceptionally gentle and kind personality made him much appreciated by a wide circle of friends. When relaxed he was most entertaining company and he was always helpful in the lives and work of his colleagues and students. He will be widely missed and our deepest sympathy goes to Mrs P.A. Caldwell and their children Helen, Margaret, Philip, Anne and Thomas.

E.J. Denton

\section{John Jaeger}

Professor JohN CONRAD JAEger, Emeritus Professor of Geophysics in the Australian National University, died on 15 May 1979 after a long illness, at the age of 71.

Born in Sydney on 30 July 1907, he was educated at the Church of England Grammar School, Sydney, and at the University of Sydney from which he graduated Bachelor of Science in 1928 with first class honours and university medals in mathematics and physics. In that year he went to Cambridge University where he received first class honours in the Mathematical Tripos. Following five years of research at Cambridge in theoretical physics, he joined the University of Tasmania in 1936 as Lecturer in Mathematics, subsequently becoming Professor of Applied Mathematics in that University. In 1942 he was awarded the degree of Doctor of Science in the University of Sydney.

Shortly after the founding of the Australian National University, John Jaeger was invited to accept a Chair and to set up a Department in the Research School of Physical Sciences. He took up his appointment as Professor and Head of the Department of Geophysics in 1952, and remained in that post until his retirement in 1972. Under his direction, the Department of Geophysics developed rapidly into one of the leading research groups of its kind in the world. In 1965, it became the Department of Geophysics and Geochemistry and more recently (1973), was reconstituted to form the Research School of Earth Sciences, at least in part in recognition of the high international reputation that the department established under John Jaeger's leadership.

The direction of development of the deparment was largely based upon his strongly held belief that the application of the basic sciences of mathematics, physics and chemistry, in concert with more conventional geological methods, to the study of the earth, would result in major advances in our understanding of the origin and history of the earth. His recognition of the importance of interdisciplinary fields, together with his ability to attract staff and students, were major factors in establishment of the high reputation of the department, both nationally and internationally, in a relatively short period.

John Jaeger had a most distinguished career as mathematician, physicist and geophysicist. His scientific contributions covered an extraordinarily diverse range of interests, including theoretical physics, radiophysics, ionospheric and solar physics and meteorology, but the main emphasis of his research was in the application of mathematical techniques to a wide variety of theoretical and practical problems, especially the conduction of heat. On establishing the Department of Geophysics in the Australian National University he embarked upon vigorous experimental programmes concerned with heat flow in the Australian continent, and the behaviour of rocks under stress (rock mechanics). John Jaeger was a man of great scholastic achievement; he published more than 130 articles in the scientific literature, and was author or coauthor of six books in applied mathematics and rock mechanics, which are regarded as standard works in their fields. His book (with Carslaw) The Conduction of Heat in Solids is widely accepted as a classic in this area.

In recognition of his achievements, Jaeger, in 1954, was elected a Fellow of the Australian Academy of Science, of which body he was Vice-President in 1958-1959, and in 1970 he was elected Fellow of the Royal Society (London). He was also Doctor of Science (honoris causa) of the University of Tasmania. In 1971, he was awarded the Rankine Lecture by the Institution of Civil Engineers (London).

John Jaeger was a big man, both physically and mentally. He was a man of great humanity but basically very shy. He never sought the limelight and was extremely modest about his own achievements. He set high standards for himself and expected staff and students alike to strive for excellence. His influence in many fields, including the earth sciences, in Australia and indeed in the world, has been profound. He will be sorely missed.

Ian McDougall

\section{J.B. Birks}

DR JOHN B. BIRKS, reader in physics at Manchester University died suddenly on 1 March 1979, a few months after the death of his wife Margaret in a car accident. $\mathrm{He}$ leaves a son and daughter.

He was born on 6 March 1920. After graduation from Oxford in 1940 he joined the Telecommunications Research Establishment for the duration of the war. His work there on radar led to his work on microwave absorption in ferrites, when he joined the Department of Natural Philosophy at Glasgow and for which he received his $\mathrm{PhD}$ in 1947. An interest in scintillation counters led him into the field of scintillators and the photophysics of organic molecules which became his main scientific interest.

In 1951 he became professor of physics at Rhodes University, South Africa, where he quickly established an active research group. However, his dislike of the developing racial policies made him return to Britain in 1954 as diretor of research at British Dielectric Research. In 1957 he moved to Manchester to resume his work on photophysics and in a few years had built up a large and thriving research group which later, with his encouragement, diversified into electron scattering, lasers, microwave spectroscopy, vacuum ultraviolet spectroscopy and latterly, polymer physics.

An empiricist, he was probably most gifted in correlating the mass of data in the field and extracting the essence. He had a good physical insight and made substantial contributions to his subject. A prolific and fluent writer he published some 180 papers, edited the proceedings of many conferences, e.g. the Rutherford Jubilee International Conference 1961, and the series Progress in Dielectrics. $\mathrm{He}$ is probably best known for his books Scintillation Counters (1953), Theory and Practice of Scintillation Counting (1964), Photophysics of Organic Molecules (1970) and the two volumes of Organic Molecular Photophysics (1974). Several monographs on scintillation counting were widely distributed by several companies in the field. He was a consultant to many companies and national laboratories, in demand as a seminar speaker and a great attender of conferences where he met his many friends who will now sadly miss his stimulating presence. An enthusiast for his subject he was on occasions guilty of going a bit over the top but his friends would readily forgive him.

John Birks was a man of wide culture and liberal humanistic views, and was always prepared to defend what he thought was right and to support his friends. Never an establishment man he clashed with authority on several occasions which possibly affected his career. A most efficient and capable administrator, and an excellent teacher and researcher he had much to offer.

He was a generous host who entertained well and was particularly kind to his students, many of whom came from overseas. He made them feel very much at home, and now, spread around the world, they will be saddened by his death.

The loss of his wife was a great blow. They will both be greatly missed by his son and daughter and their families. I am glad that for 28 years I knew him both as friend and colleague.

Scott Hamilton 